\title{
RESEARCH
}

\section{PREVALENCE OF PHYSICAL RESTRAINT: A CROSS-SECTIONAL OBSERVATIONAL STUDY}

Turkish Journal of Geriatrics DOI: $10.31086 /$ tigeri.2020.175 2020; 23(3): 384-392

\section{- Burcu AKPINAR SÖYLEMEZ' D \\ - Özlem KÜÇÜKGÜÇLÜ1 1 D \\ - Bilgehan ÖZKAYA' D \\ - Ecem ÖZGÜL² (D)}

CORRESPONDANCE

Burcu AKPINAR SÖYLEMEZ

Dokuz Eylul University, Department of Internal

Medicine Nursing , İzmir, Turkey.

Phone: +902324124793

e-mail: burcu.akpinar@deu.edu.tr

Received: Mar 09, 2020

Accepted: Jun 15, 2020

\section{Abstract}

Introduction: Physical restraint (PR) is commonly used in healthcare institutions worldwide and controversial strategies in the medical field. The purpose of this study was to determine the PR prevalence in adult patients at a university hospital in Turkey.

Materials and Methods: An observational and cross-sectional design was carried out. Prevalence rates were computed. A total of 6698 patients in 30 units were evaluated at 10 unit visits between July-September 2018. Patient and PR information form was used. Two researchers visited the units and proceeded with data collection. The study population consisted of all patients who were present in the hospital on the day of data collection.

Results: Among 6698 patients, 287 (4.3\%) patients were restrained. The highest overall prevalence of $69.6 \%$ was in the surgical intensive care unit (ICU). The main reasons reported for using restraints were the prevention of pulling out medical devices $(47 \%)$. Age $(p=0.000)$ and units (e.g., surgical units, ICUs) $(p=0.000)$ were statistically significant predictors of PR. Age $(p=.000)$ and units $(p=.000)$ were statistically significant predictors of PR. The results show that for every additional 0.038 year in patients age, the patient becomes 1.038 times more likely to be restrained.

Conclusion: In Turkey, the rate of application of PR is similar to that of world figures. Age is a very important variable in the use of PR. As they get older, their risk of being exposed to PR increases.

Keywords: Patients; Prevalence; Nurses
Dokuz Eylul University , Department of Internal Medicine Nursing , Izmir, Turkey.

Izmir University of Economics, Department of Internal Medicine Nursing, Faculty of Health Sciences, İzmir, Turkey 


\section{INTRODUCTION}

Physical restraint (PR) can be defined as connecting physical or mechanical devices to the patient's body or applying short-term physical force by a healthcare professional to the patient in order to restrict the mobility and to prevent easy movements $(1,2)$. PR is commonly used in healthcare institutions all over the world and remains to be one of the controversial strategies (3-7).

Use of restraint or failure to comply with established procedures may harm the patient physically, socially, and psychologically $(1,7,8,9$, 10). Attempts should be made to reduce the PR detection rate and possible harm brought about by PR. It is important that nurses are willing to develop new strategies in order to reduce the rate of PR and possible harm.

\section{Background}

Several reports on the PR prevalence have been published by some countries and different healthcare institutions. In a PR study by Minnick et al. (11) conducted in intensive care units (ICUs) in the United States, it was reported that the prevalence of PR use was 50/1000 patients per day. In a study conducted in a hospital in Germany, the prevalence of PR was found to be $11.8 \%$ (12). Additionally, in a study carried out in ICUs in the Netherlands, PR prevalence was found to be $23 \%$. The prevalence of PR in a nursing home in Spain was reported to be $20 \%$ (13), and it was reported to be $84.9 \%$ in another study conducted in long-term care centers (3). The prevalence of PR in a hospital in Israel was reported to be $2 \%-7.5 \%$ (6) and $23 \%$ in a hospital study conducted by Kalula and Petros (5) in South Africa. In a study conducted in ICUs in Jordan, the prevalence of PR use was found to be $35.8 \%$ (14). Limited number of studies were conducted in ICUs in Turkey $(1,15,16)$, and no study was conducted involving all units in hospital. The current study is the first study identifying the prevalence of PR of all adult units in one hospital

\section{in Turkey.}

In the studies, the features of patients at the risk of PR application were also investigated. Patients at the risk for PR are as follows: the elderly (12), those who are more dependent on nursing care, those who are sedated, those with aggressive behavior (17), those attached to mechanical ventilators (18), and those who are comatose (19). Other situations that may subject patients to PR are the work environment and workload of nurses (1). Determining the characteristics of patients subjected to PR is very important for the identification of patients at risk.

PR is generally considered and applied for the benefit of the patient, such as preventing the patient from falling off the bed; preventing them from pulling out the connected tubes, drains, and medical devices; and ensuring control over the patient's behaviors $(3,16,20)$. However, improper use of restraint material or failure to comply with established procedures may harm the patient physically, socially, and psychologically. These physical damages include decreased muscle tone, orthostatic hypotension, urinary and fecal incontinence, increased risk of nosocomial infection, edema of the lower extremities, pressure sores, chronic constipation, contracture, malnutrition, pneumonia, skin and tissue injuries, and muscular atrophy $(1,9)$. The negative psychological and social effects include fear, increased confusion, panic, anger, cognitive and behavioral symptoms, increased anxiety, insomnia, delirium, shame, resistance and disobeying, decreased self-esteem, decreased self-confidence, apathy, depression, and impaired body image $(7,8,10)$. Regulations and standards for PR procedures have been set in many countries to minimize the damages caused by PR. Turkey was able to set quality standards for PR in 2011 (21).

The patient and family members should be well informed about the procedure, and obtaining 
informed consents aside from physician's directive is required for the application of PR. The responses of patients to PR should be carefully and properly monitored, evaluated, and recorded. The PRs should be removed at regular intervals to check for circulation and skin condition, and patients should be assessed whether continuation of PR application is safe (20). Nurses should be aware of the specific policies and procedures for the proper use and monitoring of PR. However, the studies in Turkey showed that informed consent for PR or physician's directive were not carefully applied, registration and reporting were not carefully performed, patients were not sufficiently monitored, and the standards for PR application were not fully met $(20,22)$.

Literature review showed that there are studies identifying the prevalence of PR use in several countries $(2,3,4,5,14)$. However, none of these studies includes all units in one hospital, and their samples are not as large as the current study. Determining the prevalence of PR allows for the planning of interventions to minimize the frequency of use of PR. In addition to this, the study can help the aware of elder people who under risk for PR. To know the risk of elderly about PR can improve the elderly care. For these reasons, this study was conducted to determine the PR prevalence in adult patients hospitalized during certain periods of time at a university hospital in Turkey and to identify the characteristics of patients on PR.

\section{METHOD}

\section{Design}

An observational and cross-sectional design was carried out.

\section{Data Collection and Sample}

Data from one University Hospital, which is in the western part of Turkey, were collected. All adult units (internal medicine units, surgical units, ICUs, emergency department, psychiatry units) aside from pediatric units and operating rooms in the University Hospital were included in the study. A total of 6698 patients in 30 units were observed. Patient and physical restraint information form was used. The form was prepared by researchers to obtain information about the patient's characteristics (age, gender, clinics, NG tube, foley catether etc.) and physical restraint information (types of physical restraints, reasons for physical restraints, fall risk assessment scale). These information were obtained from their hospital records and through observation.

The total number of patient beds in adult units is 754 in this hospital. In these units, the total number of patients hospitalized in 3 months from July to September 2017 was 10.527 (requested from $X$ Hospital Information Unit). Among these studies, the research by Raguan et al. (6) in Israel with the lowest prevalence (2\%) was used for sample calculation. The study population was accepted as 10.527 , and deviation was $0.2 \%$, with 95\% confidence interval and 6191 target samples. Between July 2018 and September 2018, a total of 6698 patients were evaluated spontaneously at 10 unit visits. The study population consisted of all patients who were present in the hospital on the day of data collection to determine prevalence. There is no any special inclusion criteria.

Through simple random sampling, 10 days were selected for visit to the unit; half of the visits were during night shifts. Nurses did not know the days of the visits to prevent bias. Von Elm et al.'s (23) epidemiological observational study guide (The Strengthening the Reporting of Observational Studies in Epidemiology-STROBE) was used (See Supplementary File 1). Two researchers visited the units and proceeded with data collection. For the aim of the current study, PR was defined as any device, material, or tool attached to a patient to restrict his or her mobility and/or to prevent disruption of medical treatment. According to this definition, a patient would be considered to be 
restrained if one or more body parts were tied to the bed. This would include tying patients' wrist or ankle to their bed. After the identifying patients who were physically restrained, the researchers asked nurses reasons for restraint.

\section{Data Analysis}

Prevalence rates were computed. Data analysis was performed by the researchers using the SPSS 22.0 software. Categorical data were summarized based on their frequency, whereas continuous data were summarized based on their mean and standard deviation. Logistic regression analysis was performed and used to compute the odds ratio. Significance was set at $p<0.05$.

\section{Ethical Considerations}

Approval of conducting the study was obtained from one University Hospital and Ethical Committee of the one University Institute of Health Sciences. Informed consent was not required because the data were collected anonymously. The names or private information of patients was not recorded to prevent any ethical violation.

\section{RESULTS}

\section{Sample}

A total of 6698 patients were observed in 30 units every 2 weeks. The study is comprised of 10 observations. The mean age of the 6698 patients was 58.88 years (17.62), and $50.8 \%$ were male. The number of restrained patients was 287 ; their mean age was 70.84 years (16.81); a total of $54.7 \%$ were male; a total of $74.6 \%$ had nasogastric (NG) tube; a total of $90.2 \%$ had Foley catheter; a total of $50.5 \%$ had central venous catheter; and $56.8 \%$ were intubated (Table 1). The mean of ITAKi was 15.53 (3.46), (min-max: 6-31); all restrained patients had a high fall risk. The "iTAKi fall risk scale" is a scale consisting of 19 risk factors, including the risk factors that may cause patients to fall. Min-max score of original scale is $0-51$.

\section{Prevalence and Types of PRs}

Among the 6698 patients, 287 (4.3\%) patients were restrained. The prevalence of restraint use varied depending on the units. The highest overall prevalence of $69.6 \%$ was observed in the surgical $\mathrm{ICU}$, whereas the lowest was $0 \%$ in the psychiatry, urology, thoracic surgery, cardiovascular surgery, plastic surgery, ocular diseases, gynecologyobstetrics, physical therapy, infectious diseases, and dermatology unit. The most common types of PRs were extremity and wrist restraint (99.7\%). The least common types of PRs were the elbow restraint $(0.3 \%)$ (Table 1$)$.

\section{Reasons for PRs}

The main reasons reported by nurses for using PRs were for patients' safety (for prevention) (47.0\%), agitation (26.8\%), avoid pulling out attached medical devices (10.1\%), confusion (3.8\%), falling history (0.3\%) (Table 1).

\section{Factors Predicting PRs}

A model that integrates the variables described the restraint use. Table 2 shows the results of the logistic regression, which indicates factors predicting restraint use to patients. The model contains four predictors (age, gender, day or night shifts, units). Age $(p=0.000)$ and units $(p=0.000)$ were statistically significant predictors of PR (Table 2).

The prevalence of restraint use in the morning shifts was $46 \%$ and in night shifts was $54 \%$, and shift ( $p=0.238$ ) was not statistically a significant predictor for PR application. Gender $(p=0.979)$ was not a statistically significant predictor for PR application (Table 2).

The model explains 39\% of the observed variability in applying PR. The results show that for every additional 0.038 year in the age, the patient becomes 1.038 times more likely to be restrained. When separate models were established for each unit and age, the use of PR was found to be significant in internal disease areas (odds ratio $=$ 
Table 1. Distribution of emergency diagnoses and outcomes of the study population according to age groups

\begin{tabular}{|c|c|}
\hline Patients Characteristics & n (6698) \\
\hline $\begin{array}{l}\text { Age } \\
\qquad \text { Mean (SD) }\end{array}$ & $58.88(17.62)$ \\
\hline $\begin{array}{l}\text { Gender } \\
\text { Male (\%) } \\
\text { Female (\%) }\end{array}$ & $\begin{array}{l}3402(\% 50.8) \\
3296(\% 49.2) \\
\end{array}$ \\
\hline $\begin{array}{l}\text { Clinics } \\
\text { Internal medicine clinics } \\
\text { Surgery clinics } \\
\text { Intensive care units } \\
\text { Emergency department } \\
\text { Psychiatric clinics }\end{array}$ & $\begin{array}{l}3123(\% 46.6) \\
2586(\% 38.6) \\
480(\% 7.2) \\
274(\% 4.1) \\
235(\% 3.5)\end{array}$ \\
\hline $\begin{array}{l}\text { Shifts } \\
\text { Day } \\
\text { Night }\end{array}$ & \begin{tabular}{|l}
$3281(\% 49.0)$ \\
$3417(\% 51.0)$ \\
\end{tabular} \\
\hline Restrained Patients & n (287) \\
\hline $\begin{array}{l}\text { Age } \\
\text { Mean (SD) }\end{array}$ & $\begin{array}{l}\text { Age } \\
\text { Mean (SD) }\end{array}$ \\
\hline (ITAKI) Fall Risk Assessment Scale & $15.53(3.46)$ \\
\hline $\begin{array}{l}\text { Gender } \\
\text { Male } \\
\text { Female }\end{array}$ & \begin{tabular}{|l}
$157(\% 54.7)$ \\
$130(\% 45.3)$ \\
\end{tabular} \\
\hline $\begin{array}{l}\text { Clinics } \\
\text { Internal medicine clinics } \\
\text { Surgery clinics } \\
\text { Intensive care units } \\
\text { Emergency department }\end{array}$ & \begin{tabular}{|c|}
$46(\% 16.0)$ \\
$39(\% 13.6)$ \\
$192(\% 66.9)$ \\
$10(\% 3.5)$ \\
\end{tabular} \\
\hline $\begin{array}{l}\text { Shifts } \\
\text { Day } \\
\text { Night }\end{array}$ & \begin{tabular}{|l|}
$132(\% 46.0)$ \\
$155(\% 54.0)$ \\
\end{tabular} \\
\hline $\begin{array}{l}\text { Types of Physical Restraints } \\
\text { Wrist } \\
\text { Elbow }\end{array}$ & $\begin{array}{c}286(\% 99.7) \\
1(\% 0.3)\end{array}$ \\
\hline $\begin{array}{l}\text { Reasons for Physical Restraints } \\
\text { Prevention of pulling out medical devices } \\
\text { Agitation } \\
\text { Confusion } \\
\text { Falling history } \\
\text { History of pulling out the medical devices } \\
\text { More than one reason }\end{array}$ & \begin{tabular}{|c|}
$135(\% 47.0)$ \\
$77(\% 26.8)$ \\
$11(\% 3.8)$ \\
$1(\% 0.3)$ \\
$29(\% 10.1)$ \\
$34(\% 11.8)$ \\
\end{tabular} \\
\hline $\begin{array}{l}\text { NG tube } \\
\text { Yes } \\
\text { No }\end{array}$ & $\begin{array}{r}214(\% 74.6) \\
73(\% 25.4) \\
\end{array}$ \\
\hline $\begin{array}{l}\text { Foley catheter } \\
\text { Yes } \\
\text { No }\end{array}$ & \begin{tabular}{|c|}
259 (\%90.2) \\
28 (\%9.8)
\end{tabular} \\
\hline $\begin{array}{l}\text { Central venous catheter } \\
\text { Yes } \\
\text { No }\end{array}$ & $\begin{array}{l}145(\% 50.5) \\
142(\% 49.5) \\
\end{array}$ \\
\hline $\begin{array}{l}\text { Intubated } \\
\text { Yes } \\
\text { No }\end{array}$ & \begin{tabular}{|l}
$163(\% 56.8)$ \\
$124(\% 43.2)$ \\
\end{tabular} \\
\hline
\end{tabular}

5.555), surgical units (odds ratio $=3.485$ ), and ICUs (odds ratio $=.27$ ).

\section{DISCUSSION}

The current study is the first study identifying the prevalence of PR of all adult units in one hospital in Turkey. The hospital where the study was conducted was under the large maximumcare hospital category, which is one of Turkey's leading healthcare organizations, with a total capacity of 1000 beds. In the literature, the studies identifying the prevalence of PR were mostly on specific areas such as ICUs (14, 15, 22), long-term care centers and home cares (3). The number of studies investigating almost all adult care unit of a hospital is quite limited (4-6).

\section{Prevalence and Types of PRs}

In this study, the prevalence of PR was determined to be $4.3 \%$ in a university hospital. Eskandari et al. (4) found that the prevalence of PR was $3.39 \%$, and Raguan et al. (6) found it to be $3.51 \%$. Krüger et al. (12) determined the prevalence to be $11.8 \%$. In the study conducted by Kalula and Petros (5) in South Africa, the PR rate was found to be $23 \%$. The results of the research conducted on the prevalence of PR in hospitals are observed to be accumulated in a wide range of $2 \%-25 \%$ (12). It is thought that this situation is caused by the different units involved in the prevalence studies. The prevalence of PR is observed to be high in studies where ICUs are involved $(4,12)$. In this current study, it can be observed that the highest prevalence of PR is in ICUs when comparing the units. This is similar to the results of other studies (12). In addition, because the definition of PR in the study and the protocols applied depending on the countries are different, the prevalence may differ in line with the researches. An important variable in terms of differences is the attitude of health care professionals toward PR. It is thought that the knowledge, attitude, and experiences of nurses on the subject matter are important. In 
Turkey, the standards for PR were defined in 2011, and patient's safety was taken into the scope of quality. It is known that there is a lack of training programs accessible to every nurse in the country. In a study by Bakır et al. (22) conducted in Turkey that is related to the attitude toward PR and application of PR (2016), more than half of the respondents (73.8\%) gave wrong answers in the information section about PR. As a result of this research, it can be accepted that the issue of PR use has not yet been fully adopted.

In the current study, the most common types of PRs were wrist restraints (99.7\%). In the literature, it can also be seen that wrist restraints are commonly used. Eskandari et al. (4) reported that $83.4 \%$ of the individuals were restrained from their wrists. In the study by Turgay et al. (16), it was also reported that wrist and ankle restraints were commonly used. Suliman (14) stated that the most common restraint type was wrist or finger restraints. The most common reason for PR explained by nurses was to prevent patient from pulling out attached medical devices from their bodies, which can be prevented by restraining the wrists.

\section{Reasons of PRs}

Similarly, in other studies, it was found that most of patients were subjected to PRs for the purposes of prevention (4, 5, 16). Eskandari et al. (4) stated

Table 2. The relationship between patient variables and SF-36 scores of caregivers

\begin{tabular}{|c|c|c|c|c|c|c|c|}
\hline \multirow{2}{*}{ Predictors } & \multirow{2}{*}{ B } & \multirow{2}{*}{ SE } & \multirow{2}{*}{ Wald } & \multirow{2}{*}{ Odds ratio } & \multicolumn{2}{|c|}{$95 \% \mathrm{Cl}$ Odds ratio } & \multirow{2}{*}{$P$ value } \\
\hline & & & & & Lower & Upper & \\
\hline Age & .038 & .005 & 60.104 & 1.038 & 1.029 & 1.048 & $.000^{*}$ \\
\hline Gender & -.004 & .143 & .001 & .996 & .752 & 1.319 & .979 \\
\hline Shift & -.168 & .142 & 1.393 & .845 & .640 & 1.117 & .238 \\
\hline $\begin{array}{l}\text { Internal } \\
\text { medicine } \\
\text { clinics }\end{array}$ & 1.715 & .164 & 108.912 & 5.555 & 4.025 & 7.665 & $.000^{*}$ \\
\hline Surgery clinics & 1.248 & .176 & 50.559 & 3.485 & 2.470 & 4.916 & $.000^{*}$ \\
\hline $\begin{array}{l}\text { Intensive care } \\
\text { units }\end{array}$ & -3.595 & .142 & 638.828 & .27 & .21 & .36 & $.000^{*}$ \\
\hline $\begin{array}{l}\text { Emergency } \\
\text { department }\end{array}$ & 451 & .332 & 1.849 & 1.570 & .819 & 3.010 & .174 \\
\hline $\begin{array}{l}\text { Psychiatric } \\
\text { clinics }\end{array}$ & 17.544 & 2491.951 & .000 & .000 & .000 & - & .994 \\
\hline \multicolumn{2}{|c|}{ Hosmer and Lemeshow Test } & \multicolumn{2}{|c|}{ Chi-square } & df & $P$ value & & \\
\hline & & \multicolumn{2}{|l|}{39.290} & 8 & $.000^{\star}$ & & \\
\hline \multicolumn{2}{|c|}{-2Log likelihood } & \multicolumn{2}{|c|}{ Cox \& Snell R square } & \multicolumn{2}{|c|}{ Nagelkerke R square } & & \\
\hline \multicolumn{2}{|l|}{1544.033} & \multicolumn{2}{|l|}{.116} & \multicolumn{2}{|l|}{.389} & & \\
\hline
\end{tabular}


that the reason for the use of PR was to prevent patients from pulling out attached tubes and catheters. In this study, when the characteristics of patients being restrained are analyzed, it can be seen that $74.6 \%$ had NG tube; a total of $90.2 \%$ had Foley catheter; a total of $50.5 \%$ had central venous catheter; a total of $56.8 \%$ were intubated; and $10.1 \%$ had history of pulling out attached medical devices. Based on the ITAKi fall risk scale, the mean score was 15.53. Nurses consider PR as an application to be performed for the patient's safety (20).

\section{Factors Predicting of the PRs}

Older age and gender. In our study, it was concluded that the age variable posed a risk for PR and that the elderly patients displayed higher prevalence of PR. In the literature, Heinze et al. (24) and Krüger et al. (12) also found that the use of PR increased with age. The results of the research conducted by Suliman (14) in the literature on age are striking. Suliman (14) found that patients were more likely to be bound to their beds in a younger age and that this situation was attributed to the fact that young patients are stronger and are attached to more medical devices. However, in the same study, it was seen that the mean age of the sampling was 60.2 years, and it was also observed that the group sample studied was younger than those in other studies. This difference is thought to be because of having a young sampling group.

Whether or not gender is a risk factor for the use of PR is a controversial issue. In the current study, it was found that there was no difference between the two genders. Likewise, Suliman (14) and Luk et al. (17) found that gender was not associated with the PR use. In studies that found gender to be influential, Eskandari et al. (4), Kalula and Petros (5), and Raguan et al. (6) found that male patients had higher incidence of PR. In contrast, Heinze et al. (24) found that female patients had higher incidence of PR.

Day and night shifts. In the literature, it is emphasized that the frequency of PR application is higher during night shifts $(4,6,15)$. Eskandari et al. (4) found that patients were more likely to be restrained in the night shifts (psychiatric wards $87.3 \%$, nonpsychiatric wards $82.9 \%$ ), and Akansel (15) found this value to be $87.3 \%$ in the night shift. Suliman (14) found that the rate of PR application was 3.6 times more during night shifts and stated that nurses are more likely to restrain patients during busy times and in busy places. During night shifts, the shortage in healthcare workers may make the job of supervising patients' movements more difficult for nurses. On the contrary, Minnick et al. (11) concluded in their study that the type of shift did not affect the application of PR. The current study found no difference in day and night shifts unlike other recent studies in the literature. It is thought that this is due to the similarity of day and night nurse rates in the hospital.

Comparing units. When the units were investigated separately, internal medicine units or ICUs had higher prevalence of PR. Patients in the internal medicine units have diseases such as cancer, cerebrovascular diseases, delirium, and dementia. In addition, the mean age of patients in internal medicine units is 61 years, considering that age is a significant risk factor for the application of PR. It is thought that the characteristics of patients' diseases and higher mean age increase the risk for PR. Although there are more young patients admitted to surgical units, it is thought that PR are used because of the state of consciousness caused by surgery, excessive catheter, and presence of drainage.

The mean age of patients hospitalized in ICUs is 66 years. Patients admitted to ICUs have many features such as sedation, delirium development, changes in consciousness levels, intubation, and presence of catheters and drains. It is well known in the literature that more PRs are used because of the characteristics of patients in ICUs $(14,15)$. Similarly, the highest rate of PR application was 
found in ICUs (66.9\%).

The use of PR in psychiatric units is a controversial issue in the literature. Eskandari et al. (4) stated that there is a rate of $13.6 \%$ of PR use in psychiatric units. However, contrary to this study, Kalula and Petros (5) concluded that no PR was applied in psychiatric units. This is thought to be related to "seclusion" or "mechanical restraint" or "physical restraints" used in psychiatric units.

There is not enough information in the literature on the use of PR in emergency departments. Wong et al. (25) stated that only $0.5 \%$ patients had restraint orders in emergency departments. In the current study, being admitted to emergency departments did not pose a risk for PR. This situation is thought to be because of the fact that there are generally acute cases in emergency departments. It was concluded that very few patients admitted to the emergency department had to be restrained because of clouding of consciousness and deterioration of the general condition.

\section{REFERENCES}

1. Demir A. Nurses' use of physical restraints in four Turkish hospitals. J Nurs Scholarsh 2007;39(1):38-45. (PMID: 17393964).

2. Fariña-López E, Estévez-Guerra GJ, Gandoy-Crego M, Polo-Luque LM, Gómez-Cantorna C, Capezuti E. Perception of Spanish nursing staff on the use of physical restraints. J Nurs Scholarsh 2014;46(5): 322330. (PMID: 24754778).

3. Estévez-Guerra GJ, Fariña-López E, Núñez-González E, Gandoy-Crego M, Calvo-Francés F, Capezuti EA. The use of physical restraints in long-term care in Spain: a multi-center cross-sectional study. BMC Geriatr 2017;17(1):29. (PMID: 28109267).

4. Eskandari F, Abdullah KL, Zainal NZ, Wong LP. Incidance rate and patterns of physical restraint use among adult patients in Malaysia. Clin Nurs Res 2018;27(3):278-295. (PMID: 27856788).

\section{CONCLUSION}

In Turkey, the rate of PR application is similar to that of the worldwide figures, and often they are applied in general hospitals. Age is a very important variable to be considered in $P R$ application. As patients get older, their risk of being exposed to PR increases. The prevalence of $P R$ is varied depending on units. Being in internal medicine, admission to surgical and intensive care units increases the probability of the use of PRs on patients. In this study, it was concluded that day or night shifts or gender does not pose a risk for PR.

\section{Relevance to Clinical Practice}

Determination of prevalence of PR allows for the planning of interventions to minimize the frequency of use of PR. With this study, the PR prevalence in the general hospital has been revealed. In particular, ICUs are the places where PR is most commonly used. Older patients are under risk to PR. Therefore, attempts should be made to reduce the PR detection rate, especially in these places. This study may help nurses to find new strategy in ensuring safety that is less restrictive.

5. Kalula SZ, Petros SG. Use of physical restraint in hospital patients: A descriptive study in a tertiary hospital in South Africa. Curationis 2016;39(1): e1-e8. (PMID: 28155298).

6. Raguan B, Wolfovitz E, Gil E. Use of physical restraints in a general hospital: A cross-sectional observational study. Isr Med Assoc J 2015;17(10):633-8. (PMID: 26665319).

7. Shanahan D. Bedrails and vulnerable older adults: How should nurses make 'safe and sound' decisions surrounding their use? Int J Older People Nurs 2012;7(4):272-81. (PMID: 21722323).

8. Eşer I, Hakverdioglu G. Deciding on using a physical restraint. Journal of Cumhuriyet University School of Nursing 2006;10(1):37-42. (in Turkish)

9. Hofmann $H$, Hahn S. Characteristics of nursing home residents and physical restraint: A systematic 
literature review. J Clin Nurs 2014;23: 3012-24. (PMID: 24125061)

10. Strout T. Perspectives on the experience of being physically restrained: An integrative review of the qualitative literature. Int $\mathrm{J}$ Ment Health Nurs 2010;19(6):416-27. (PMID: 21054728).

11. Minnick AF, Mion LC, Johnson ME, Catrambone C, Leipzig R. Prevalence and variation of physical restraint use in acute care settings in the US. J Nurs Scholarsh 2007;39(1):30-7. (PMID: 17393963).

12. Krüger $C$, Mayer $H$, Haastert B, Meyer $G$. Use of physical restraints in acute hospitals in Germany: A multi-centre cross-sectional study. Int J Nurs Stud 2013;50(12):1599-606. (PMID: 23768409).

13. Galán CM, Trinidad D, Ramos $P$, et al. Use of physical restraints in an elderly population living in public nursing homes. Rev Esp Geriatr Gerontol 2008;43(4):208-13. (PMID: 18682141).

14. Suliman M. Prevalence of physical restraint among ventilated intensive care unit patients. J Clin Nurs 2018;27(19-20):3490-3496. (PMID: 29943878).

15. Akansel, N. Physical restraint practices among ICU nurses in one university hospital in weastern Turkey. Health Science Journal 2007; 1(4):1-6.

16. Turgay AS, Sarı D, Genc RE. Physical restraint use in Turkish Intensive care units. Clin Nurse Spec 2009; 23(2):68-72. (PMID: 19225286).

17. Luk E, Sneyers B, Rose L, et al. Predictors of physical restraint use in Canadian intensive care units. Crit Care 2014;18(2):R46. (PMID: 24661688).

18. Unoki T, Sakuramoto $H$, Ouchi A, et al. Physical restraints in intensive care units: a national questionnaire survey of physical restraint use for critically ill patients undergoing invasive mechanical ventilation in Japan. Acute Med Surg 2018;6(1):68-72. (PMID: 30652000).

19. Van der Kooi AW, Peelen LM, Raijmakers RJ, et al. Use of physical restraints in Dutch intensive care units: A prospective multicenter study. Am J Crit Care 2015;24(6):488-495. (PMID: 26523006).

20. Kılıç G, Kutlutürkan S, Çevik B, Erdoğan B. The evaluation of Intensive care unit nurses' opinions on physical restraint application. Van Medical Journal 2018; 25(1), 11-16. (in Turkish).

21. Ministry of Health, Performance Management Quality Improvement Department. Hospital Service Quality Standards 2011; Ankara. [Internet] Available from: https://dosyamerkez.saglik.gov.tr/ Eklenti/6116,sksenglish-2013pdf.pdf?0. Accessed: 06.03.2020

22. Bakır E, Şahin G, Dişel NR, Akpınar AA. The Knowledge, attitude and practices regarding to physical detection (FTE) application of health service providers working in emergency service in Adana. Zirve Medical Journal 2016; 1(1):10-16. (in Turkish).

23. Von Elm E, Altman DG, Egger M, Pocock SJ, Gøtzsche PC, Vandenbroucke J P. Strengthening the reporting of observational studies in epidemiology (STROBE) statement: guidelines for reporting observational studies. BMJ 2007;335(7624):806-8. (PMID: 17947786)

24. Heinze C, Dassen T, Grittner U. Use of physical restraints in nursing homes and hospitals and related factors: a cross-sectional study. J Clin Nurs 2012;21(78):1033-1040. (PMID: 22176771).

25. Wong AH, Taylor RA, Ray JM, Bernstein SL. Physical restraint use in adult patients presenting to a general emergency department. Ann Emerg Med 2019;73(2):183-192. (PMID: 30119940) 